\title{
Pengaruh Luas Perpindahan Panas Kondensor Terhadap Volume Asap Cair Terkondensasi Hasil Pirolisis Tempurung Kelapa
}

\author{
Nurkholis $^{1}$, Siti Jamilatun ${ }^{2 *}$ \\ ${ }^{1,2}$ Program Studi Teknik Kimia FTI UAD, Kampus III, Jl. Supomo, Janturan, Warungboto, Yogyakarta \\ 55164 \\ *e-mail: sitijamilatun_uad@yahoo.com.
}

\begin{abstract}
One of the products that can be made from coconut shell is to make charcoal by pyrolysis. Pyrolysis also produces liquid smoke, tar, and uncondensed gasses. Liquid smoke is a byproduct of the activated charcoal industry which has high economic value. Liquid smoke is a substance derived from the change of state into the coolant fumes which involves the heat transfer. Liquid smoke is obtained simultaneously with the production of charcoal (carbonization) and the smoke from incomplete combustion. The purposes of this study were to determine the heat transfer surface area $(A)$ in the manufacture of liquid smoke and the relationship between heat transfer surface area (A) and the liquid smoke volume. The stages of the study consist of designing of equipment, burning of coconut shell and measuring the volume of liquid smoke. The results showed that the highest liquid smoke volume of $215 \mathrm{~mL}$ was obtained on the weight of coconut shell of $8 \mathrm{~kg}$ and condenser of 8 pipes with a pyrolysis time of 90 minutes and the theory of heat transfer surface area of $0.076965 \mathrm{~m}^{2}$.
\end{abstract}

Keywords: Coconut shell, pyrolysis, liquid smoke, condenser

\section{Pendahuluan}

Indonesia sebagai negara agraris dan maritim telah dikaruniai kekayaan sumber daya alam yang luar biasa. Penduduk Indonesia yang berjumlah lebih dari 210 juta orang merupakan sumber daya potensial untuk mengolah sumber daya alam tersebut. Pendekatan pembangunan ekonomi nasional berdasarkan potensi kekayaan alam menghasilkan produk dan jasa yang bernilai ekonomi terbatas. Kekayaan alam yang melimpah tersebut selama ini justru dimanfaatkan sebagai bahan baku untuk industri manufaktur di negara lain.

Indonesia merupakan salah satu negara penghasil kelapa terbesar di dunia. Hal ini telah menjadikan kelapa sebagai salah satu penggerak utama, pemicu dan pemacu ekonomi Indonesia. Prestasi ekonomi untuk ekspor dan pasar domestik serta luas perkebunan tahun 2001 sebesar 3.584.486 Ha, demikian pula dukungan 10 perseroan terbatas perkebunan (PTP) $(13 \%, 573.518 \mathrm{Ha}), 14$ grup swasta besar $(51 \%, 1.828 .088 \mathrm{Ha}) \mathrm{dan}$ perkebunan rakyat $(33 \%, 1.828 .880 \mathrm{Ha})[1]$.

Kelapa (Cocos nucifera L.) merupakan komoditas strategis yang memiliki peran sosial, budaya dan ekonomi dalam kehidupan masyarakat Indonesia [2]. Bagian-bagian dari tanaman kelapa yang dapat dimanfaatkan oleh masyarakat antara lain: air kelapa, daging kelapa dan tempurung kelapa [3]. Kelapa merupakan tanaman tropis yang telah lama dikenal masyarakat Indonesia. Hal ini terlihat dari penyebaran tanaman kelapa di hampir seluruh wilayah nusantara, yaitu di Sumatera dengan luas 1,20 juta ha (32,90\%), Jawa 0,903 juta ha $(24,30 \%)$, Sulawesi 0,716 juta ha $(19,30 \%)$, Bali, NTB dan NTT 0,305 juta ha $(8,20 \%)$, Maluku dan Papua 0,289 juta ha $(7,80 \%)$ dan Kalimantan 0,277 juta ha (7,50\%) [4,5]. Sejak tahun 1988 Indonesia menduduki urutan pertama sebagai negara yang memiliki areal kebun kelapa terluas di dunia. Dari seluruh luas areal perkebunan kelapa, sekitar 97,4\% dikelola oleh perkebunan rakyat yang melibatkan sekitar 3,1 juta keluarga petani. Sisanya sebanyak $2,1 \%$ dikelola perkebunan besar swasta dan $0,5 \%$ dikelola perkebunan besar negara [6].

Kelapa dikenal sebagai tanaman yang serbaguna karena seluruh bagian tanaman ini bermanfaat bagi kehidupan manusia serta mempunyai nilai ekonomis yang cukup tinggi. Salah satu bagian yang terpenting dari tanaman kelapa adalah buah kelapa. Buah kelapa terdiri dari beberapa komponen yaitu kulit luar (epicarp), sabut (mesocarp), tempurung kelapa (endocarp), daging buah (endosperm), dan air kelapa. Adapun komposisi buah kelapa dapat kita lihat pada Tabel 1 [7]. 
Tabel 1. Komposisi Buah Kelapa

\begin{tabular}{cc}
\hline Bagian Buah & Jumlah Berat (\%) \\
\hline Sabut & 35 \\
Tempurung & 12 \\
Daging buah & 28 \\
Air kelapa & 25 \\
\hline
\end{tabular}

Pengarangan tempurung kelapa dapat dilakukan dengan pirolisis. Pirolisis merupakan proses fraksinasi material oleh suhu. Produk pirolisis terdiri dari tiga jenis yaitu gas $\left(\mathrm{H}_{2}, \mathrm{CO}, \mathrm{CO}_{2}, \mathrm{H}_{2} \mathrm{O}\right.$ dan $\left.\mathrm{CH}_{4}\right)$, tar dan arang [8]. Tetapi dengan meningkatnya produksi arang aktif yang menggunakan bahan dasar tempurung kelapa maka akan mengakibatkan terjadinya pencemaran udara karena adanya penguraian senyawa-senyawa kimia dari tempurung kelapa pada proses pembakaran. Pada proses pirolisis juga dihasilkan asap cair, tar dan gas-gas yang tak terembunkan. Asap cair yang merupakan hasil sampingan dari industri arang aktif tersebut mempunyai nilai ekonomi yang tinggi jika dibandingkan dengan dibuang ke atmosfir.

Asap cair adalah suspensi koloid yang mengandung partikel cair dan uap yang diperoleh dari pirolisis [9]. Asap cair mengandung berbagai senyawa penyusun utama asam, fenol dan karbonil [10]. Proses pembuatan asap cair melibatkan proses perpindahan panas dari asap ke zat pendingin. Terjadinya proses perpindahan panas adalah atas dasar hukum Termodinamika yang kedua yang menyatakan bahwa energi cenderung mengalami degenerasi menjadi energi yang lebih rendah. Pengendalian gas dengan kondensasi lebih sederhana dan murah peralatannya, umumnya digunakan air atau udara sebagai media pendingin. Jika gas yang panas berkontak dengan media pendingin (air atau udara), maka terjadi transfer panas dari gas panas ke medium pendingin, temperatur uap gas akan turun, maka energi kinetik molekul gas akan berkurang sehingga molekul-molekul gas akan bergerak saling berdekatan (Gaya Van der Waals) yang menyebabkan gas terkondensasi menjadi liquid. Banyaknya asap cair yang dihasilkan pada proses kondensasi tergantung pada luas permukaan perpindahan panas per satuan waktu. Semakin besar luas permukaan perpindahan panas, semakin banyak pula gas yang terkondensasi menjadi asap cair. Asap cair dalam aplikasinya secara luas dapat digunakan dalam industri pangan sebagai pemberi rasa, aroma dan pengawet, serta dapat digunakan sebagai koagulan lateks di industri perkebunan [9]. Oleh karena itu, penelitian ini bertujuan untuk mengetahui luas permukaan perpindahan panas $(\mathrm{A})$ yang dibutuhkan pada proses pembuatan asap cair dan mengetahui hubungan antara luas permukaan perpindahan panas (A) dengan volume asap cair yang dihasilkan.

\section{Metodologi}

\section{Bahan dan Alat}

Bahan yang digunakan pada penelitian ini adalah tempurung kelapa dan air pendingin. Alat-alat yang digunakan antara lain: tangki stainless steel ukuran diameter $58 \mathrm{~cm}$ dan tinggi $70 \mathrm{~cm}$, tangki stainless steel ukuran diameter $36 \mathrm{~cm}$ dan tinggi $46 \mathrm{~cm}$, thermocouple, stop watch, shok pipa besi 1/2 in dan 3/4 in, besi penyangga, pipa besi $1 / 2$ in, kawat kasa 1 lembar, seng 1 lembar, timbangan, selang, wadah penampung liquid smoke, tangki kondensasi, tabung gas, alat pembakar, kran air dan botol penyimpan asap cair.

\section{Tahap Perancangan Alat}

Mempersiapkan tangki stainless yang diperlukan sesuai dengan ukuran dan spesifikasi yang telah direncanakan, kemudian menutup bagian atas tangki sesuai dengan desain yang telah direncanakan. Selanjutnya, membuat lubang pada bagian atas tangki sebagai lubang tempat pemasangan kondensor serta penampungan tar dan merangkai tangki destilasi dan kondensasi sesuai gambar rancangan. Tahap berikutnya menghitung jumlah panas (Q) yang diserap dan luas permukaan perpindahan panas (A) dan mengukur volume asap cair yang dihasilkan

\section{Tahap Persiapan}

Tahap pertama membentuk masing-masing bagian alat dan menyambung di bengkel las, kemudian merangkai alat pembakaran yang telah dibentuk sesuai rancangan gambar untuk produksi arang.

\section{Tahap Pembakaran}

Menimbang tempurung kelapa sesuai kebutuhan dan memasukkan ke dalam tangki pembakaran yang sebelumnya sudah diberi kawat kasa agar tempurung kelapa tidak menutupi alat pembakaran dan ada celah udara. Menyalakan api dengan cara yaitu dengan menyalakan alat pembakaran yang dihubungkan pada selang tabung gas. Setelah menyala, masukkan ke dalam tangki pembakaran lewat lubang bagian bawah. Setelah beberapa saat setelah api mulai rata membakar tempurung kelapa api dimatikan dengan cara menutup kran 
aliran gas pada tabung gas dan alat pembakaran dikeluarkan dari tangki. Lubang tempat memasukkan dan mengeluarkan alat pembakaran ditutup kembali.

Asap cair yang melewati pipa dan menuju tangki destilasi dan kondensasi mulai terbentuk dan ditampung, dicatat waktu dan jumlah asap cair yang terbentuk tiap 30 menit. Asap cair di tangki destilasi akan melewati bagian atas yang mempunyai titik didih rendah (kualitas bagus) dan tertampung di bagian bawah yang mempunyai titik didih tinggi yang berupa cairan kental. Asap yang keluar bagian atas tangki destilasi kemudian akan melewati tangki kondensor untuk diembunkan. Suhu di tangki pembakaran dan tangki destilasi dicatat setiap 30 menit. Proses pembakaran diulangi untuk jumlah pipa kondensor yang berbeda (4 pipa dan 8 pipa). Rangkaian alat pembentukan asap cair dapat dilihat pada Gambar 1.

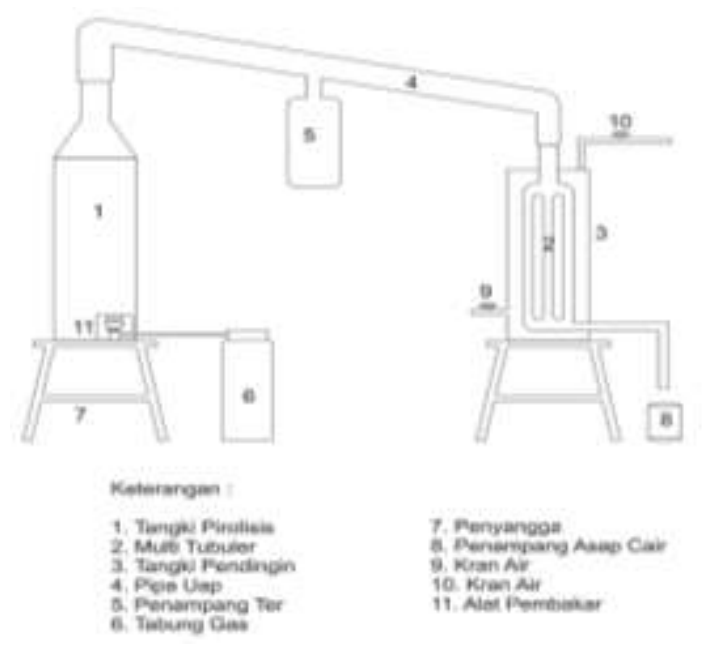

Gambar 1. Rangkaian alat pembentukan asap cair

\section{Hasil dan Pembahasan}

Hubungan antara Luas Perpindahan Panas dan Volume Asap Cair (Berat Tempurung Kelapa 5 kg)

Hasil pengukuran volume asap cair dan luas perpindahan panas dari berat tempurung kelapa $5 \mathrm{~kg}$ disajikan pada Gambar 2.

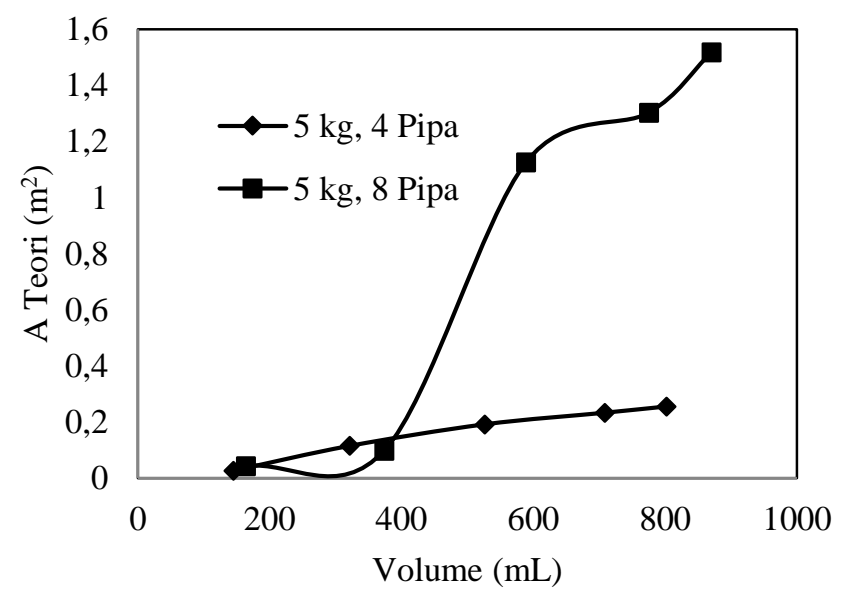

Gambar 2. Hubungan antara luas perpindahan panas dan volume asap cair (berat tempurung kelapa $5 \mathrm{~kg}$ )

Dari gambar 2 dapat disimpulkan hubungan antara volume asap cair dan luas permukaan perpindahan panas (A). Untuk berat tempurung kelapa $5 \mathrm{~kg}$ dengan kondensor 4 pipa $(\mathrm{D}=0,01905 \mathrm{~m} ; \mathrm{H}=0,8 \mathrm{~m})$ dan 8 pipa (D $=0,01905 \mathrm{~m} ; \mathrm{H}=0,8 \mathrm{~m})$, semakin besar luas permukaan perpindahan panas maka akan semakin banyak pula uap hasil pembakaran yang dapat terkondensasi. Semakin banyak jumlah pipa pada kondensor yang digunakan, semakin besar pula luas permukaan perpindahan panas. Luas permukaan perpindahan panas ini akan mempengaruhi volume asap cair yang dihasilkan. 
Luas permukaan perpindahan panas yang optimal untuk berat tempurung kelapa $5 \mathrm{~kg}$ dan kondensor 4 pipa adalah sebesar $0,076965 \mathrm{~m}^{2}$ yang dapat menghasilkan asap cair $205 \mathrm{ml}$. Sedangkan luas permukaan perpindahan panas yang optimal untuk berat tempurung kelapa $5 \mathrm{~kg}$ dan kondensor 8 pipa adalah sebesar $1,027437 \mathrm{~m}^{2}$ yang dapat menghasilkana asap cair sebesar $215 \mathrm{ml}$. Besarnya luas permukaan perpindahan panas teori dipengaruhi oleh suhu pirolisis dan suhu kondensasi.

\section{Hubungan antara Luas Perpindahan Panas dan Volume Asap Cair (Berat Tempurung Kelapa 10 kg)}

Hasil pengukuran volume asap cair dan luas perpindahan panas dari berat tempurung kelapa $10 \mathrm{~kg}$ ditampilkan pada Gambar 3.

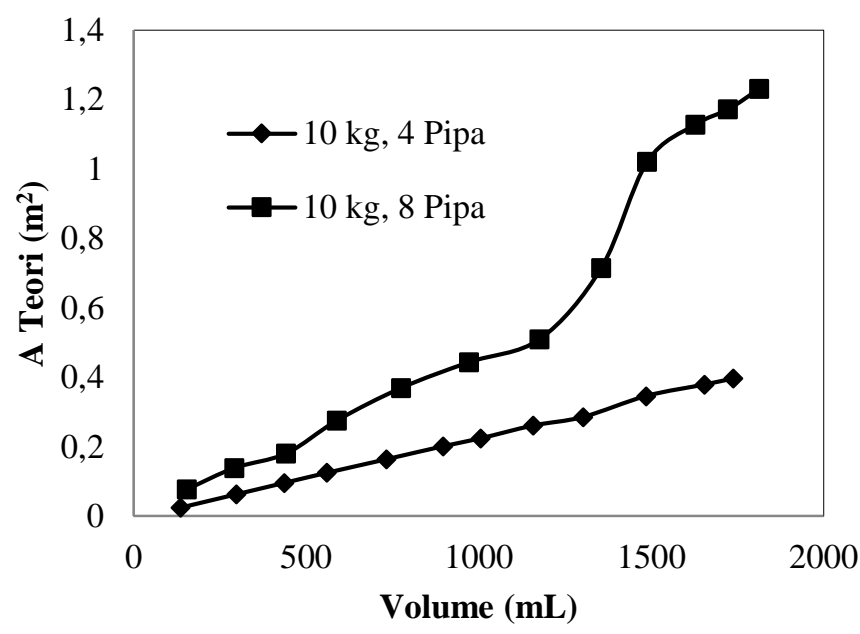

Gambar 3. Hubungan antara luas perpindahan panas dan volume asap cair (berat tempurung $10 \mathrm{~kg}$ )

Dari gambar 3 dapat disimpulkan hubungan antara volume asap cair dan luas permukaan perpindahan panas (A). Untuk berat tempurung kelapa $10 \mathrm{~kg}$ dengan kondensor 4 pipa $(\mathrm{D}=0,01905 \mathrm{~m} ; \mathrm{H}=0,8 \mathrm{~m})$ dan 8 pipa (D $=0,01905 \mathrm{~m} ; \mathrm{H}=0,8 \mathrm{~m}$ ), semakin besar luas permukaan perpindahan panas maka akan semakin banyak pula uap hasil pembakaran yang dapat terkondensasi. Semakin banyak jumlah pipa pada kondensor yang digunakan, semakin besar pula luas permukaan perpindahan panas. Luas permukaan perpindahan panas ini akan mempengaruhi volume asap cair yang dihasilkan.

Luas permukaan perpindahan panas yang optimal untuk berat tempurung kelapa $10 \mathrm{~kg}$ dan kondensor 4 pipa adalah sebesar $0,060404 \mathrm{~m}^{2}$ yang dapat menghasilkan asap cair sebesar $183 \mathrm{ml}$. Luas permukaan perpindahan panas yang optimal untuk berat tempurung kelapa $10 \mathrm{~kg}$ dan kondensor 8 pipa adalah sebesar $0,066801 \mathrm{~m}^{2}$ yang dapat menghasilkan asap cair sebesar $205 \mathrm{ml}$. Besarnya luas permukaan perpindahan panas teori dipengaruhi oleh suhu pirolisis dan suhu kondensasi.

\section{Kesimpulan}

Dari hasil penelitian dapat diambil kesimpulan bahwa semakin lama waktu pirolisis, maka semakin besar volume asap cair yang dihasilkan. Volume asap cair terbesar dan luas perpindahan panas terbesar diperoleh pada berat tempurung kelapa $5 \mathrm{~kg}$ dan 8 pipa dengan waktu pirolisis 90 menit.

\section{Daftar Pustaka}

[1] Darmaji, P. 2000. Optimasi produk dan sifat fungsional asap cair kayu karet. Agritech. 20(3).

[2] Hartawan, R. dan Sarjono, A. 2016. Karakteristik fisik dan produksi kelapa dalam (Cocos Nucifera L) di berbagai ekologi lahan. Jurnal Media Pertanian. 1(2):45-54.

[3] Pratiwi, F. M. dan Sutara, P. K. 2013. Etnobotani kelapa (Cocos nucifera L.) di wilayah Denpasar dan Bandung. Jurnal Simbiosis. 1(2): 102-111.

[4] Supadi dan Nurmanaf, A. R. 2006. Pemberdayaan petani kelapa dalam upaya peningkatan pendapatan. Jurnal Litbang Pertanian. 25(1): 31-36.

[5] Nogoseno. 2003. Reinventing agribisnis per- kelapaan nasional. Prosiding Konferensi Nasional Kelapa V. Tembilahan, 22-24 Oktober 2002. Pusat Penelitian dan Pengembangan Perkebunan, Bogor. 17-27.

[6] Palungkun, R. 2003. Aneka Produk Olahan Kelapa. Cetakan ke Sembilan. Penebar Swadaya, Jakarta.

[7] Setiadji, B. 2000. Asap Cair. CV. PPKT, Yogyakarta. 
[8] Ramadhan, A. dan Munawar, A. 2012. Pengolahan sampah plastik menjadi minyak menggunakan proses pirolisis. Jurnal Ilmiah Teknik Lingkungan. 4(1): 44-53.

[9] Prasetyowati, Novianty, A. P., dan Haryuni, M. R. 2014. Pembuatan asap cair dari limbah kulit singkong (Manihot Esculenta L. SKIN) untuk bahan pengawet kayu. Teknik Kimia. 20(1): 64-75.

[10] Pamori, R., Efendi, R., dan Restuhadi, F. 2015. Karakteristik Asap Cair dari Proses Pirolisis Limbah Sabut Kelapa Muda. Sagu. 14(2): 43-50. 